\title{
Risk factors for cardiac, obstetric, and neonatal complications in patients with heart disease during pregnancy
}

\section{Factores de riesgo para complicaciones cardíacas, obstétricas y neonatales en pacientes con enfermedad cardíaca durante el embarazo}

\author{
Edison Muñoz-Ortiz"1,2*, Jairo A. Gándara-Ricardo1,2, Jesús A. Velásquez-Penagos ${ }^{1,3}$, \\ Natalia Giraldo-Ardila4, Ana M. Betancur-Pizarro', Edwin F. Arévalo-Guerrero', \\ Fernando M. Fortich-Hoyos ${ }^{1}$, and Juan M. Senior-Sánchez ${ }^{1,2}$ \\ ${ }^{1}$ Cardiopulmonary and Peripheral Vascular Function Unit, Cardio-obstetric Clinic, Hospital Universitario San Vicente Fundación; ${ }^{2}$ Department of \\ Internal Medicine, Cardiology Section; ${ }^{3}$ Department of Gynecology and Obstetrics, Perinatology and Obstetric High Risk Section, Universidad de \\ Antioquia, Antioquia; ${ }^{4}$ Neonatal Unit, Hospital General de Medellín. Medellin, Colombia
}

\begin{abstract}
Objective: Heart disease in pregnancy can cause clinical deterioration and maternal-fetal death. It is essential to evaluate risk factors related to complications. Methodology: This was a observational, analytical retrospective cohort study with a non-probabilistic convenience sample of pregnant women with congenital or acquired heart disease, corrected or not, or arrhythmias requiring urgent intervention. Patients with mild or moderate valvular regurgitation, mild valvular stenosis, patients without echocardiography or without delivery information were excluded from the study. The outcome was a composite of cardiac, obstetric, and neonatal events. Univariate and multivariate analyzes were performed with logistic regression model and discriminatory capacity with area under the curve and independent analysis of the modified World Health Organization ( $\mathrm{mWHO}$ ) risk classification ( $\mathrm{mWHO}$ ). Results: $A$ total of 104 patients with an average age of $25 \pm 6.5$ years presented cardiac events in $13.5 \%$, obstetric in $14.42 \%$, and neonatal in $28.85 \%$. The univariate analysis found an association with New York Heart Association functional status, hypertensive disorders of pregnancy, cesarean delivery, gestational age $<27$ weeks, hypoxemia, and mWHO risk. In multivariate only cesarean delivery (odds ratio [OR], 2.68; 95\% confidence interval [CI], 1.056.86) and gestational age at delivery $(\mathrm{OR}, 0.39 ; 95 \% \mathrm{Cl}, 0.22-0.67)$ maintain association with outcomes. The area under the curve for the $\mathrm{mWHO}$ risk is 0.75 . Conclusions: There is a high rate of adverse events in patients with heart disease during pregnancy. Gestational age and cesarean delivery behaved as predictors of adverse maternal-fetal outcomes. The mWHO risk classification had an acceptable prediction of adverse outcomes.
\end{abstract}

Key words: Pregnancy. Heart disease. Maternal complications. Neonatal complications.

E-mail: edison.munoz@sanvicentefundacion.com 2604-7063 / @ 2019 Instituto Nacional de Cardiología Ignacio Chávez. Published by Permanyer. This is an open access article under the CC BY-NC-ND license (http://creativecommons.org/licenses/by-nc-nd/4.0/).

Available online: 04-09-2020 Arch Cardiol Mex (Eng). 2020;90(2):101-107 www.archivoscardiologia.com
Date of reception: 05-05-2019 Date of acceptance: 19-07-2019 


\section{Resumen}

Objetivo: La enfermedad cardíaca en el embarazo puede ocasionar deterioro clínico y muerte maternofetal. Es indispensable evaluar factores de riesgo relacionados con complicaciones. Método: Estudio observacional y analítico de cohorte retrospectivo con muestra no probabilística por conveniencia de embarazadas con cardiopatía congénita o adquirida, corregida o no, o arritmias que requerían intervención urgente. Se excluyó a pacientes con insuficiencias valvulares leves o moderadas, estenosis valvulares leves, pacientes sin ecocardiografía o sin información del parto. El desenlace fue un compuesto de episodios cardíacos, obstétricos y neonatales. Se realizó análisis univariado y multivariado con modelo de regresión logística y capacidad diferenciadora con área bajo la curva y análisis independiente de la clasificación de riesgo de la OMS modificada (OMSm). Resultados: 104 pacientes con edad promedio de $25 \pm 6.5$ años presentaron episodios cardíacos en $13.5 \%$, obstétricos en $14.42 \%$ y neonatales en $28.85 \%$. El análisis univariado encontró una relación con el estado funcional de la NYHA, trastornos hipertensivos del embarazo, parto por cesárea, edad gestacional < 27 semanas, hipoxemia y riesgo de la OMSm. En el multivariado sólo el parto por cesárea (OR, 2.68; IC 95\%, 1.05-6.86) y la edad gestacional al momento del parto (OR, 0.39; IC 95\%, 0.22-0.67) mantienen nexo con los desenlaces. El área bajo la curva para el riesgo de la OMSm es de 0.75. Conclusiones: Hay una elevada tasa de efectos adversos en pacientes con enfermedad cardíaca durante el embarazo. La edad gestacional y el parto por cesárea se comportaron como predictores de resultados adversos maternofetales. La clasificación de riesgo de la OMSm tuvo una predicción aceptable de desenlaces adversos.

Plabras clave: Embarazo. Cardiopatía. Complicaciones maternas. Complicaciones neonatales.

\section{Introduction}

Cardiovascular disease in pregnant patients has an approximate prevalence of $1-4 \%$ and causes $10-15 \%$ of maternal mortality ${ }^{1,2}$. Gestation represents a pressure for the cardiovascular system, not only because of the $50 \%$ increase in blood volume and cardiac output but also due to cardiac structural changes, as well as vascular and metabolic modifications ${ }^{3}$. This explains the risk for decompensation and death in women with heart disease during pregnancy. In Colombia, $39 \%$ of maternal deaths are the result of indirect causes, i.e., those resulting from a condition established before pregnancy or that evolves during its course and that is not related to obstetric causes; of the total number of these indirect causes, $3.7 \%$ corresponds to heart disease ${ }^{4}$.

Given the specific epidemiological and sociocultural characteristics of the country ${ }^{5}$, the pattern of heart disease occurrence and its effect on maternal-fetal morbidity and mortality, assessing associated factors becomes essential to timely detect them.

\section{Methodology}

This was a observational, analytical, and retrospective cohort study with a non-probabilistic convenience sample. The sample consisted of 104 pregnant patients who were admitted to the obstetrics department of a high-complexity institution between January 1, 2010, and December 31, 2015, including patients with congenital or acquired heart disease, corrected or not, and with arrhythmias requiring urgent hospital treatment.
Medical histories from both the mother and the newborn were reviewed using a case report form for the collection of information using the Microsoft Excel software, and the data were subsequently analyzed with STATA 13. A cardiologist, a neonatologist, and an obstetrician-gynecologist corroborated the cardiovascular, neonatal, and obstetric outcomes, respectively. Individuals with mild or moderate valve insufficiency, those with mild valve stenosis according to the 2017 European Society of Cardiology/European Association for Cardio-Thoracic Surgery guidelines ${ }^{6}$ criteria and subjects who lacked an echocardiographic study or delivery information were excluded.

Variables taken from patient history included demographic data such as age, parity status, gestational age at first evaluation by the cardiology department and at delivery, habits (smoking and alcohol consumption), comorbidities according to current guidelines' definitions (hypertension, diabetes mellitus, dyslipidemia, and other conditions that implied adopting chronic treatment), cardiovascular history (surgical or percutaneous cardiovascular interventions before pregnancy, heart disease, or complication before pregnancy), oxygen saturation at admission, presence of cyanosis, chronically consumed drugs, and with an emphasis on anticoagulants (indication, type, and follow-up). Regarding echocardiographic findings, left ventricle ejection fraction, presence or not of right ventricular dilatation, and type of detected heart disease were reviewed. The route of delivery was verified and, in case of cesarean 
delivery, whether the indication was obstetric or cardiac was reviewed.

Maternal-fetal and obstetric hospital outcomes were classified as follows:

- Primary cardiac events: pulmonary edema, sustained symptomatic arrhythmia requiring treatment (tachyarrhythmia or bradyarrhythmia), stroke, cardiac arrest, or cardiac death.

- Secondary cardiac events: deterioration of two or more New York Heart Association (NYHA) classes in comparison with baseline, need for urgent invasive cardiac procedure during pregnancy or in-hospital postpartum period.

- Neonatal episodes: premature delivery $(<37$ weeks of gestation), low weight for gestational age (lower than $10^{\text {th }}$ percentile), respiratory distress syndrome, intraventricular hemorrhage, stillbirth ( $\geq 20$ weeks of gestation), or neonatal death (up to postpartum day 28). In addition to neonatal episodes, the presence of abortion was investigated ( $<20$ weeks of gestation).

- Obstetric episodes: non-cardiac maternal death, hypertensive disorder of pregnancy (HDP), and postpartum hemorrhage $(>500 \mathrm{~mL}$ in vaginal delivery or $>1000 \mathrm{~mL}$ in cesarean section).

\section{Statistical analysis}

Categorical variables are summarized in absolute and relative values, and for continuous variables, normality assumption was carried out with the ShapiroWilk test. Variables with normal distribution are summarized with averages and standard deviation, and variables that did not meet the normality assumption, with medians, and interquartile range. The outcome measure was a composite of cardiac, obstetric, and neonatal episodes. Univariate analysis was performed for the proposed risk variables using the Chi-square test, Fisher's exact test, or the t-test for single samples and Mann-Whitney's U-test for continuous data. A wide spectrum of variables was considered (Table 1) to identify determinants of the proposed outcome; univariate analysis predictors $(p<0.25)$ were included in a multivariate analysis with a logistic regression model, and its discrimination capacity was determined with the area under the curve; after the logistic regression, a generalized linear model with logit function was constructed to compare the results of the two alternative methods and generate the same outcome prediction. The modified World Health Organization (mWHO) risk
Table 1. Patient general characteristics

\section{Variable}

Age in years, median (range)

Number of previous pregnancies, median (range)

Gestational age at delivery in weeks, median (range)

Gestational age at first evaluation by the cardiology department in weeks, median (range)

Oxygen saturation $\%$ at admission (range)

$94.7(50-100)$

Smoking history: number of patients (\%)

Never

Former smoker

Active consumption

$99(95.1)$

$4(3.85)$

$1(0.96)$

Alcohol consumption during pregnancy:

number of patients $(\%)$

No

Yes

$102(98.08)$

2 (1.92)

Functional status classified at admission:

number of patients $(\%)$

\begin{tabular}{|c|c|}
\hline NYHA I & $77-(74.04)$ \\
\hline NYHA II & $17-(16.35)$ \\
NYHA III & $7-(6,73)$ \\
NYHA IV & $3-(2.88)$
\end{tabular}

Modified WHO risk: number of patients $(\%)$

II

III

IV

$12(11.54)$

$59(56.73)$

16 (15.38)

$17(16.35)$

Echocardiographic findings

Ejection fraction \% (range)

Right ventricular dilatation: number of patients (\%)

No

$61(20-85)$

Yes

80 (76.92)

24 (23.08)

Comorbidities: number of patients (\%)

Hypertension

Hypothyroidism

Hyperthyroidism

Type 2 diabetes mellitus

$12(11.5)$

Cerebrovascular disease

$4(3.8)$

$1(0.96)$

Ischemic stroke

Pulmonary embolism

$2(1.92)$

$2(1.92)$

Systemic lupus erythematosus

Takayasu's arteritis

$1(0.96)$

Mixed connective tissue disease

Antiphospholipid syndrome

2 (1.92)

$1(0.96)$

$1(0.96)$

Immune thrombocytopenic purpura

Epilepsy

$1(0.96)$

$1(0.96)$

HIV infection

$1(0.96)$

$1(0.96)$ 
Table 1. Patient general characteristics (Continued)

\section{Variable} $\mathrm{n}=\mathbf{1 0 4}$

Chronically used medications: number of patients $(\%)$

None

Calcium antagonists

Methyldopa $\alpha$

Furosemide

ACEI

ASA

$\alpha$-blocker

Levothyroxine

Enoxaparin

Steroids

Warfarin

ARA-II

Spironolactone

Chloroquine

Azathioprine

Sildenafil

Hydrochlorothiazide

Metformin

Clonidine

Digoxin

$5(72.12 \%)$

5 (4.8)

$5(4.8)$

$5(4.8)$

$5(4.8)$

$5(4.8)$

$4(3.85)$

$4(3.85)$

4 (3.85)

3 (2.88)

$3(2.88)$

$1(0.96)$

$1(0.96)$

$1(0.96)$

$1(0.96)$

$1(0.96)$

$1(0.96)$

$1(0.96)$

$1(0.96)$

$1(0.96)$

Anticoagulation indication: number of patients (\%)

None

98 (94.23)

Mechanical heart valve

$4(3.85)$

Venous thromboembolism

$1(0.96)$

Thrombophilia

$1(0.96)$

Anticoagulation type: number of patients (\%)

None

98 (94.23)

Warfarin

2 (1.92)

Enoxaparin without measuring anti-Xa

values

Warfarin followed by enoxaparin without

measuring anti-Xa values

3 (2.88)

$1(0.96$

ARA-II: angiotensin II receptor antagonists; ASA: acetylsalicylic acid; ACEl: angiotensin-converting enzyme inhibitors, NYHA: New York Heart Association.

classification and its differentiation capacity were independently analyzed.

\section{Results}

A total of 104 patients with an average age of $25 \pm 6.5$ years and an average gestational age of $32 \pm 8$ weeks at cardiologic evaluation were included in the study, out of whom $74 \%$ were in NYHA functional Class I (Table 1).

Congenital heart disease was the most common primary diagnosis in the assessed pregnant women with $51.92 \%$, followed by valvular heart disease with $25.95 \%$, arrhythmias with $15.38 \%$, and left ventricular dysfunction with $4.81 \%$. Other less frequent heart alterations were idiopathic pulmonary arterial hypertension and cardiac tumors with $0.96 \%$ each (Fig. 1). Specific heart

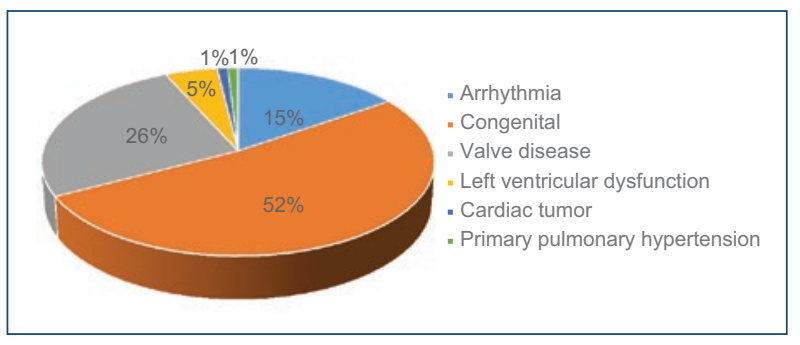

Figure 1. Types of heart disease found as main diagnosis.

condition diagnoses and their frequency of occurrence are described in table 2.

Primary cardiac episodes occurred in $13.5 \%$ of cases and the most common was pulmonary edema in $8.65 \%$ of patients. Obstetric events were observed in $14.42 \%$ and neonatal events in $28.85 \%$ of cases. The delivery route was cesarean section in $50 \%$ of patients; however, the majority had obstetric indications $(39 \%)$, and only $11 \%$ was due to heart disease.

In the univariate analysis, the outcome was found to be related to the following factors: NYHA functional class, HDP, cesarean delivery, gestational age of $<27$ weeks, hypoxemia, and mWHO risk classification (Table 3). Gestational age was associated with adverse outcomes; however, this was limited to neonatal episodes, as it was expected.

In the multivariate analysis, only two factors maintain an association with the outcome: delivery route by cesarean section (odds ratio [OR], 2.68; $95 \% \mathrm{Cl}, 1.05$ 6.86 ) and gestational age at delivery (OR, 0.39; 95\% $\mathrm{Cl}, 0.22-0.67)$. When included in the model, the NYHA functional class, multiparity, right ventricular dilatation, pulmonary blood pressure, delivery route, gestational age at delivery, and oxygen saturation variables showed a Chi-square of $60(p=0.000)$, pseudo-R2 of 0.58 and area under the curve of 0.93 .

\section{mWHO risk classification ( $\mathrm{mWHO}$ )}

The $\mathrm{mWHO}$ risk classification showed the following results: mWHO I with positive outcome, 3/12 (25\%); mWHO II, 16/59 (27\%); mWHO III, 10/16 (62.5\%); and mWHO IV, 16/17 (94\%) (tendency Chi-square, 23.21; $p=0.000001)$. When the mWHO I risk classification (lower-risk heart disease) was taken as reference and compared with $\mathrm{mWHO}$ II classification, MantelHaenszel (MH) OR is $1.11(95 \% \mathrm{Cl}, 0.26-4.65)$; with $\mathrm{mWHO} \mathrm{III}, \mathrm{MH}$ OR is $5(0.95-26.1)$, and with $\mathrm{mWHO} \mathrm{IV}$, MH OR is 48 (4.32-532). The area under the curve for 
Table 2. Specific cardiac diagnoses and frequency of occurrence

\begin{tabular}{|c|c|}
\hline Variables & $\mathbf{n}=\mathbf{1 0 4}$ \\
\hline Mitral valve regurgitation, $\mathrm{n}(\%)$ & $11(10.6)$ \\
\hline Patent ductus arteriosus, $\mathrm{n}(\%)$ & $10(9.62)$ \\
\hline Ventricular septal defect, $\mathrm{n}(\%)$ & $10(9.62)$ \\
\hline $\begin{array}{l}\text { Ventricular septal defect with Eisenmenger } \\
\text { syndrome, } \mathrm{n}(\%)\end{array}$ & $2(1.92)$ \\
\hline Ventricular septal defect + atrial septal defect, $n(\%)$ & $4(3.85)$ \\
\hline $\begin{array}{l}\text { Ventricular septal defect with Eisenmenger syndrome } \\
\text { + persistent truncus arteriosus, } \mathrm{n}(\%)\end{array}$ & $1(0.96)$ \\
\hline Atrial septal defect, $n(\%)$ & $8(7.69)$ \\
\hline Atrial septal defect + abnormal venous drainage, $\mathrm{n}(\%)$ & $1(0.96)$ \\
\hline $\begin{array}{l}\text { Supraventricular tachycardia due to re-entry } \\
\text { phenomenon, } \mathrm{n}(\%)\end{array}$ & $8(7.69)$ \\
\hline $\begin{array}{l}\text { Bivalve aorta without stenosis or severe } \\
\text { insufficiency, } \mathrm{n}(\%)\end{array}$ & $6(5.77)$ \\
\hline Left ventricular dysfunction, $\mathrm{n}(\%)$ & $5(4.81)$ \\
\hline Double mitral lesion, $\mathrm{n}(\%)$ & $5(4.81)$ \\
\hline Mechanical valve, $\mathrm{n}(\%)$ & $3(2.88)$ \\
\hline Ebstein anomaly, $(\%)$ & $3(2.88)$ \\
\hline Increased ventricular automaticity, $\mathrm{n}(\%)$ & $3(2.88)$ \\
\hline Corrected aortic coarctation, $\mathrm{n}(\%)$ & $3(2.88)$ \\
\hline Advanced AV block without previous pacemaker, $\mathrm{n}(\%)$ & $2(1.92)$ \\
\hline Mitral stenosis, $\mathrm{n}(\%)$ & $2(1.92)$ \\
\hline Congenital pulmonary stenosis, $\mathrm{n}(\%)$ & $2(1.92)$ \\
\hline Aortic stenosis, $\mathrm{n}(\%)$ & $2(1.92)$ \\
\hline $\begin{array}{l}\text { Mitral valve regurgitation + aortic valve regurgitation, } \\
\mathrm{n}(\%)\end{array}$ & $1(0.96)$ \\
\hline $\begin{array}{l}\text { Congenitally corrected transposition of the great } \\
\text { arteries + mechanical valve + pacemaker, } \mathrm{n}(\%)\end{array}$ & $1(0.96)$ \\
\hline Infective endocarditis, $\mathrm{n}(\%)$ & $1(0.96)$ \\
\hline Biological prosthetic valve, $\mathrm{n}(\%)$ & $1(0.96)$ \\
\hline Presence of pacemaker due to complete AV block, $\mathrm{n}(\%)$ & $1(0.96)$ \\
\hline Aortic valve regurgitation, $\mathrm{n}(\%)$ & $1(0.96)$ \\
\hline Corrected tetralogy of Fallot, $\mathrm{n}(\%)$ & $1(0.96)$ \\
\hline Primary pulmonary arterial hypertension & $1(0.96)$ \\
\hline Atrial tachycardia, $\mathrm{n}(\%)$ & $1(0.96)$ \\
\hline Uncorrected tetralogy of Fallot, $\mathrm{n}(\%)$ & $1(0.96)$ \\
\hline Atrial fibrillation, $\mathrm{n}(\%)$ & $1(0.96)$ \\
\hline Corrected AV canal, n (\%) & $1(0.96)$ \\
\hline Fibroelastoma, n (\%) & $1(0.96)$ \\
\hline
\end{tabular}

differentiation (receiver operating characteristic [ROC] curve) is 0.75 , with adequate calibration (hearing level >0.05) (Fig. 2).

\section{Discussion}

Patients with heart disease during pregnancy are at high risk of both cardiac and obstetric and neonatal episodes, as explained not only by the stress imposed by gestational changes but also by the socioeconomic profile, which in the setting of the authors includes late evaluation at a high complexity center and lack of preconception assessment. NYHA functional class, HDPs, cesarean section as delivery route, gestational age of $<27$ weeks, hypoxemia, and mWHO risk classification behave as predictors of adverse events in the univariate analysis, although only the delivery route and gestational age retain their predictive capacity in the multivariate analysis. These variables have a good discriminating capability (ROC, 0.93$)$ in the logistic regression model; nevertheless, given the low number of outcomes, they should be considered only exploratory.

The mWHO risk classification for heart disease and pregnancy has an acceptable discriminating capacity (ROC, 0.75), and it is therefore confirmed that it should be the risk scale to be used in this scenario; in addition, it allows monitoring to be planned and early interventions to be defined; this shows that each one of the groups has a different risk when compared with the first one (mWHO I; tendency Chi-square), although the confidence interval $(\mathrm{Cl})$ crosses 1 in the $\mathrm{mWHO}$ II and III risk groups, which is explained by the sample size, which generates imprecise Cls. This is consistent with recent data from the European Registry of Pregnancy and Cardiac, where the main causes of adverse primary outcomes (maternal death and heart failure) occurred in patients with mWHO IV conditions, such as pulmonary hypertension and cardiomyopathy?

In most cases, the route of choice for delivery is vaginal, since cesarean section is reserved for obstetric indications ${ }^{8}$ and for complex or decompensated heart disease, since it attenuates changes observed with labor, which could aggravate disorders such as aortic dissection and aortic root dilatation of more than 45 $\mathrm{mm}$, severe valve stenosis of the left side, highly severe cases of pulmonary hypertension, or established heart failure; in these conditions, cesarean section would allow better invasive and non-invasive monitoring ${ }^{1,9}$; however, it is associated with higher risk of postpartum hemorrhage, infection, surgical accidents, and thromboembolic episodes, which are further increased when 
Table 3. Risk factors and adverse outcomes in heart disease and pregnancy (univariate analysis)

\begin{tabular}{|l|c|c|c|c|c|}
\hline Variable & - Outcome & + Outcome & Total & $\chi^{2}$ & 0.019 \\
\hline NYHA & 59 & 45 & 104 & 9.98 & 0.154 \\
\hline Pregnancy $>2$ & 17 & 19 & 36 & 2.02 & 0.000 \\
\hline Hypertension during pregnancy & 0 & 10 & 10 & 14.5 & 0.38 \\
\hline Ejection fraction $<40 \%$ & 1 & 2 & 3 & 0.74 & 0.21 \\
\hline RV dilatation & 11 & 13 & 24 & 1.5 & 0.08 \\
\hline Pulmonary arterial hypertension & 27 & 28 & 55 & 3.06 & 0.000 \\
\hline Cesarean delivery route & 24 & 28 & 52 & 19.6 & 14.5 \\
\hline Gestational age $<27$ weeks & 0 & 10 & 10 & 0.000 \\
\hline Hypoxemia & 0 & 5 & 5 & 104 & 0.009 \\
\hline WHO classification & 59 & 45 & 28.21 & 0.000 \\
\hline
\end{tabular}

*Neonatal episodes; $\chi^{2}$ of $93.2 ; p=0.000$; obstetric episodes, $\chi^{2}$ of $0.27, p=0.59$; primary cardiac episodes, $\chi^{2}$ of $0.06, p=0.8$.

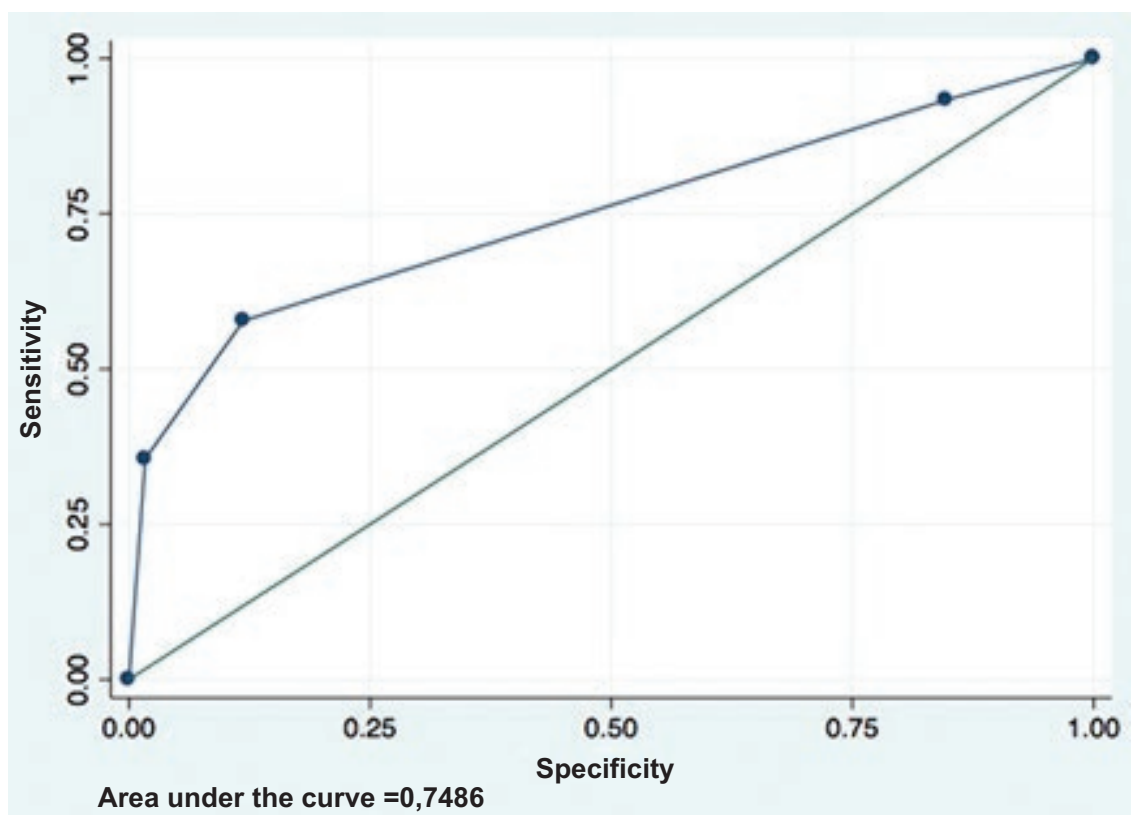

Figure 2. Receiver operating characteristic curve modified World Health Organization risk classification.

urgently performed. These are possibly the reasons why it persists as a predictor in the multivariate analysis in the described cohort. Pregnancy termination, either vaginally or by cesarean section, should be planned and, protocols for care should be previously established by a multidisciplinary and experienced group to improve the outcomes.

Gestational age is related to adverse events, particularly neonatal, as it would be expected due to vulnerability of the fetus when it is far from term, as described in other cohorts ${ }^{9,10}$. The elevated rate of adverse effects in patients with heart disease during pregnancy forces to develop multidisciplinary programs for the care of this vulnerable population, which overcome socioeconomic barriers, especially in relation to late care, which on average occurred at 32 weeks of gestation in this cohort, which has produced a marker of adverse outcomes in a recent study (when 
the first assessment has place after 20 weeks of gestational age $)^{11}$. The current cohort, developed as a prelude to organizing a cardio-obstetric group in a high-complexity center, supports this need. This study's limitations include its retrospective nature; however, the follow-up of a current prospective cohort, with earlier intervention, will allow to change the horizon and determine with higher accuracy the predictive factors of adverse episodes and develop specific scales adjusted to local reality. On the other hand, the retrospective nature of the trial itself prevented the development of scales that enabled echocardiographic studies inter-observer and intra-observer variability to be determined. Nevertheless, the echocardiography department has strict adherence to the American Society of Echocardiography recommendations for obtaining diagnostic images.

\section{Conclusions}

Pregnant women with heart disease in this cohort had a late evaluation, which in part could have led to the high rate of adverse effects. Gestational age of $<27$ weeks and delivery by cesarean section behaved as predictors of maternal-fetal adverse results in the multivariate analysis. On the other hand, mWHO risk classification independent evaluation was acceptably predictive of adverse outcomes and is suitable for assessment and planning of patient follow-up. The search for risk factors that help predict adverse outcomes in pregnant patients with heart disease is essential to achieving a quality multidisciplinary care that allows improving the results.

\section{Conflicts of interest}

The authors declare that they have no conflicts of interest.

\section{Funding}

Hospital Universitario San Vicente Fundación Research Unit and Universidad de Antioquia.

\section{Ethical disclosures}

Protection of people and animals. The authors declare that no experiments on humans or animals were performed for this investigation.

Confidentiality of data. The authors declare that they have followed the protocols of their work center on the publication of patient data.

Right to privacy and informed consent. The authors declare that no patient data appear in this article.

\section{References}

1. Regitz-Zagrosek V, Roos-Hesselink JW, Bauersachs J, Blomstrom-Lundqvist C, Cífková R, De Bonis M, et al. 2018 ESC Guidelines for the management of cardiovascular diseases during pregnancy. The task force for the management of cardiovascular diseases during pregnancy of the European Society of Cardiology (ESC). Eur Heart J. 2018; 39:3165-3241

2. Sliwa K, Bohm M. Incidence and prevalence of pregnancy-related heart disease. Cardiovasc Res. 2014;101:554-560.

3. Liu X, Arany Z. Maternal cardiac metabolism in pregnancy. Cardiovasc Res. 2014;101(4):545-53.

4. Protocolo de vigilancia epidemiológica de la mortalidad materna. Bogotá: OPS, 2016.

5. Cárdenas LM, Cotes K, Chaparro PE, Niño JA, Paternina A, Castañeda $C$, et al. Maternal mortality in Colombia 2011: a two level ecological study. PLoS One. 2015;10(3):e0118944

6. Baumgastner H, Falk V, Bax JJ, De Bomis M, Hamm C, Holm PJ, et al. 2017 ESC/EACTS guidelines for the management of valvular heart disease. The task force for the management of valvular heart disease of the European Society of Cardiology (ESC) and the European Association for Cardio-Thoracic Surgery (EACTS). Eur Heart J. 2017;38:2739-91.

7. Roos-Hesselink J, Baris L, Johnson M, De Backer J, Otto C, Marelli A, et al. Pregnancy outcomes in women with cardiovascular disease: evolving trends over 10 years in the ESC Registry Of Pregnancy And Cardiac disease (ROPAC). Eur Heart J, 2019; [Epub ahead of print].

8. Ruys TP, Cornette J, Roos-Hesslink JW. Pregnancy and delivery in cardiac disease. J Cardiol. 2013:61(2):107-112.

9. Elkayam U, Goland S, Pieper PG, Silverside CK. High risk cardiac disease in pregnancy part I. J Am Coll Cardiol. 2016;68(4):396-410.

10. Drenthen W, Boersma E, Balci A, Moons P, Roos-Hesselink, Mulder BJ, et al. Precitors of pregnancy complicactions in women with congenital heart disease. Eur Heart J. 2010;31(17):2124-2132.

11. Silversides CK, Grewal J, Mason J, Sermer M, Kiess M, Rychel V, et al. Pregnancy outcomes in women with heart disease. The CARPREG II study. J Am Coll Cardiol. 2018;71:2419-30. 